\title{
CONSCIENTIZAR PARA ESPERANÇAR: A IMPORTÂNCIA DO LEGADO POLÍTICO-PEDAGÓGICO DE PAULO FREIRE NO SÉCULO XXI
}

\author{
RAISING AWARENESS TO HOPE: THE IMPORTANCE OF \\ PAULO FREIRE'S POLITICAL-PEDAGOGICAL LEGACY \\ IN THE 21ST CENTURY
}

\section{ACLARAR PARA ESPERANZAR: LA IMPORTANCIA DEL LEGADO POLÍTICO-PEDAGÓGICO DE PAULO FREIRE EN EL SIGLO XXI}

\author{
Rosanna Barros ${ }^{1}$ \\ http://orcid.org/0000-0002-3882-1539 \\ ${ }^{1}$ Universidade do Algarve, Faro - Portugal. E-mail: rmbarros@ualg.pt
}

\begin{abstract}
Resumo
Este artigo retoma aspetos do pensamento freiriano, que se vai matizando e complexificando ao longo do tempo, para destacar como Paulo Freire elabora uma teoria da educação em que reflete acerca das formas pelas quais o pedagógico, pensado a partir da relação pedagógica entre educador e educando, e o político, equacionado a partir das relações sociais de produção e reprodução de poder, se relacionam. Dessa perspectiva argumenta-se que, no atual contexto multicrises, esse legado é essencial para compreender e apreender melhor as forças sociais que contribuem para a criação da situação de oprimido, ou seja, aquela em que se encontram os indivíduos e os coletivos excluídos de participarem, imbricando-se e interferindo, das decisões dos centros de poder políticos, económicos e sociais.
\end{abstract}

Palavras-chave: Paulo Freire. Educação. Conscientização. Dominação e Libertação.

\begin{abstract}
This article takes up aspects of Freire's thinking, that is tinted and complexing over time, to highlight how Paulo Freire elaborates a theory of education in which he reflects on the ways in which the pedagogical, thought from the pedagogical relationship between educator and student, the politician, thought from the social relations of the production and reproduction of power, relate. From there it is argued that, the current multi-crisis context, this legacy is essential to better understand and grasp the social forces that contribute to the creation of the situation of the oppressed, that is, the one in which individuals and collectives are excluded from participating,
\end{abstract}


Barros, R.

imbricating and interfering, in the decisions of political, economic and social power centres.

Keywords: Paulo Freire. Education. Awareness. Domination and Liberation.

\section{Resumen}

Este artículo retoma aspectos del pensamiento de Freire, que se tiñe y se compleja con el tiempo, para destacar cómo Paulo Freire elabora una teoría de la educación en la que reflexiona sobre las formas en que el pedagógico, pensado desde la relación pedagógica entre educador y alumno, y lo político, pensado desde las relaciones sociales de producción y reproducción de poder, están relacionados. Desde ahí se argumenta que, en el actual contexto multicrisis, ese legado es esencial para comprender mejor las fuerzas sociales que contribuyen a la creación de la situación de los oprimidos, es decir, aquella en la que los individuos y colectivos están excluidos de participar, imbricándose e interfiriendo, de las decisiones de los centros de poder políticos, económicos y sociales.

Palabras clave: Paulo Freire. educación. conciencia. Dominación y Liberación.

\section{Introdução}

A melhor forma de celebrar o centenário do nascimento de Paulo Freire é procurar revisitar, como nos propomos a fazer neste artigo de reflexão teórica ${ }^{1}$, alguns dos principais conceitos-chave do universo temático da sua filosofia políticopedagógica, isso porque, desse contributo epistemológico, emanam os fundamentos para desenvolver, em moldes teórico-práticos, uma educação problematizadora que liberte e que, libertando, transforme, e que, transformando, emancipe (pessoal e socialmente) os oprimidos que persistem hoje, como há cem anos, sob fatores macroestruturais, que, sendo obstaculizantes, não são, porém, amovíveis.

Com efeito, nessa centúria, as circunstâncias socio-históricas nas primeiras décadas, quer do século XX, quer do século XXI, adquirem similitudes importantes quando se desenha um quadro panorâmico geral. Trata-se de contextos caraterizados por lutas ideológicas significativas, que, num caso, resultaram na hegemonia liberal e, noutro, na hegemonia conservadora de cariz neoliberal; em que existiram crises financeiras globais, com respostas impactantes a vários níveis societais e socioecológicos, num caso à luz de um capitalismo redistributivo, noutro de um capitalismo

\footnotetext{
${ }^{1}$ Este texto sintetiza e atualiza aspetos mais amplamente desenvolvidos em 2014 no capítulo: Vida e Obra de Paulo Freire: a Dialética de um Olhar Fundador para uma Educação Problematizadora que Liberta, Transforma e Emancipa. In: Barros, R.; Choti D. (orgs.). Abrindo Caminhos para uma Educação Transformadora - Ensaios em Educação Social, Filosofia Aplicada e Novas Tecnologias. Lisboa: Chiado Editora, 2014. p. 37-94.
} 
financeirizado e informacional; e em que, entre outros aspetos, ocorreram também crises sanitário-pandémicas, num caso pelo vírus do subtipo $\mathrm{H} 1 \mathrm{~N} 1$, noutro pelo vírus SARS-COV-2. A partir deste recorte sucinto, podemos compreender melhor que a regulação social da "condição de oprimid" é inerentemente complexa e encontra variáveis que se articulam em contextos políticos multi-crises para restringir os espaços de emancipação social que possam emanar de projetos societais alternativos aos propostos, recorrentemente como solução assente num discurso de crise, por minorias dominantes e que, portanto, seriam projetos mais favoráveis aos que se encontram numa condição de exclusão social.

Assim sendo, neste breve artigo ensaístico selecionámos, para reflexão e (re)apropriação hodierna, os princípios fundamentais do conceito de conscientização que, no nosso entender, alicerça os pressupostos políticos do pensamento freiriano, visando, com isso, (re)iluminar caminhos alternativos, e viáveis, para a intervenção socioeducativa transformadora, que seja de pendor, crítico, ousado e humanizador e que resista, portanto, às prioridades instrumentais que dominam hoje, mediante o paradigma da aprendizagem ao longo da vida (BARROS, 2011), o panorama da agenda da política educacional em nível global (BARROS, 2012a).

\section{As ideias em contexto - dominação e libertação no pensamento freiriano}

Quem estuda o contributo epistemológico de Paulo Freire sabe que existe uma dialética entre a sua vida e a sua obra, por esse motivo torna-se imprescindível ter em conta o contexto histórico e social dos anos de 1950 e 1960 no Brasil, em que o tema do desenvolvimento nacional domina a agenda política, propiciando a visão de uma sociedade brasileira em trânsito para a modernização, para a qual não é indiferente a construção política de uma ideologia da consciência nacional. Ora, os temas geradores do pensamento de Paulo Freire, a dominação e a libertação, são elaborados no contexto inicial da sua obra como expressão da emergência política do povo brasileiro, no sentido em que a própria época era percecionada como sendo uma época de transição a que Paulo Freire se refere a Educação como Prática da Liberdade utilizando os termos de Karl Popper, quando alude à transição de uma "sociedade fechada" para uma “sociedade aberta" (FREIRE, 1968, p. 55). 
Educar as massas populares para conquistar a "consciência crítica" significava para Paulo Freire, naquela época, sobretudo envolvê-las no processo de desenvolvimento nacional e no processo de criação de uma "mentalidade democrática". Paulo Freire interessa-se pela questão da democratização da cultura, dentro do âmbito geral da democratização fundamental, e, ao empenhar-se nesse projeto, coloca a “inadequação da educação" no centro nevrálgico da sua práxis, que é sempre reflexão e ação, tomando como referência os dados da realidade brasileira da época, que tinha vinte milhões de analfabetos, entre os quais quatro milhões eram crianças das classes populares que nunca frequentaram a escola (FREIRE, 1968, p. 109).

Ao lermos a sua obra, constatamos que Paulo Freire sempre manifestou uma preocupação em refletir, criticamente, sobre a sua prática, um modo de "estar sendo" que, em educação, considera ser a chave para que o(a) educador(a) ganhe consciência do sentido político da sua prática educativa, como afirma: "não sendo neutra, a prática educativa, a formação humana, implica opções, ruturas, decisões, estar com e pôr-se contra, a favor de algum sonho e contra outro, a favor de alguém e contra alguém" (FREIRE, 1997, p. 39). Ora, dessa postura irrequieta e crítica que o carateriza, e que nele assume os contornos de uma ética democrática e radical, nascem o seu conceito de politicidade da educação e os seus princípios fundamentais que estão presentes na sua obra, sobretudo no terreno da alfabetização de adultos. Assim, a abordagem crítica de Paulo Freire sobre educação torna-o pioneiro em conceber um método de alfabetização cuja especificidade está no entendimento que é dado à noção de alfabetização; nas suas palavras, "alfabetizar não quer dizer aprender a ler e a escrever um código linguístico, mas sim aprender a ler (compreender) e escrever (transformar) sua própria realidade" (FREIRE, 1975, p. 35). Mais do que um método de alfabetização, Paulo Freire concebe toda uma teoria educacional que traduz uma visão antropológica, ético-política e deontológica, metodológica e, inclusive, estética da educação, que vai sendo dialeticamente construída ao longo da sua obra e que enforma o que atualmente designamos como o pensamento político-pedagógico de Paulo Freire.

No cerne desse pensamento está, pois, toda uma produção epistemológica em torno do que consideramos ser os seus temas geradores: a dominação e a libertação. A sua obra seminal mais conhecida, Pedagogia do Oprimido, incide nessa problemáticachave, tratando-se de uma obra de estilo ensaístico e filosófico sobre, como o próprio nos diz, "esta coisa óbvia: assim como o opressor, para oprimir, precisa de uma teoria 
da ação opressora, os oprimidos, para se libertarem, igualmente necessitam de uma teoria de sua ação" (FREIRE, 2001a, p. 183). É desse modo que Paulo Freire elabora toda uma teoria da educação em que reflete acerca das formas pelas quais o pedagógico, pensado a partir da relação pedagógica entre educador e educando, e o político, equacionado a partir das relações sociais de produção e reprodução de poder, se relacionam.

$\mathrm{Na}$ sua abordagem crítica, é o conceito de conscientização que alicerça os seus pressupostos políticos, pelo que teceremos neste artigo ensaístico diversas considerações, tomando o essencial do seu universo temático e relacionando-o com as principais influências teóricas que intervieram, junto com as suas experiênciasaprendizagens de vida, na construção do seu entendimento e perspetiva crítica sobre educação. Uma perspetiva que nega as visões dualistas da compreensão da realidade, recusando qualquer tipo de dogmatismo e combatendo explicações assentes no determinismo.

\section{Pressupostos políticos na educação freiriana: o conceito de conscientização}

No complexo itinerário intelectual de Paulo Freire, o conceito de conscientização é um dos conceitos-chave que acompanha a progressão do seu pensamento filosófico. Trata-se de um conceito associado à teologia da libertação e aos princípios de uma esquerda católica engajada na defesa dos interesses do povo e numa busca ativa no sentido da sua libertação (BOFF, 1982), que influenciaram Paulo Freire desde muito cedo, na época da sua atividade na Divisão de Educação e Cultura do Serviço Social da Indústria (SESI) e no Movimento da Ação Católica (MAC), ou seja, logo na primeira etapa do seu percurso socioprofissional. Sobre o potencial desse conceito, Paulo Freire afirmaria que, "ao ouvir pela primeira vez a palavra conscientização, percebi imediatamente a profundidade do seu significado" (FREIRE, 1980, p. 25). Na construção teórico-conceptual dos pressupostos políticos da sua teoria da educação, esse conceito é por si reinventado, sendo posteriormente retomado diversas vezes, de forma crítica, ao longo da sua obra, de tal forma que nos parece não existir, na realidade, um conceito único de conscientização em Paulo Freire, mas diversos momentos de elaboração e aprofundamento que aparecem expostos, ao longo 
dos anos, nos diversos escritos que constituem a sua obra. No essencial, esse conceito, em Paulo Freire, vai evoluindo de um cariz psicopedagógico inicial para um caráter mais político-pedagógico subjacente.

Na primeira etapa da sua práxis político-educativa, Paulo Freire, embutido no espírito da época, tinha como meta conseguir um determinado grau de consciência nas camadas populares que lhes possibilitasse a compreensão da necessidade do desenvolvimento nacional e da democracia liberal. Nesse contexto, segundo Scocuglia (2000), a teoria da transitividade da consciência, disseminada e desenvolvida no Brasil sobretudo com a contribuição de Álvaro Vieira Pinto e dos isebianos, ideólogos do nacionalismo-desenvolvimentista, torna-se uma base teórico-filosófica fundamental para Paulo Freire que, ainda em termos visivelmente psicopedagógicos, considera "ao nível espontâneo, o homem ao aproximar-se da realidade faz simplesmente a experiência da realidade na qual está e procura. Esta tomada de consciência não é ainda a conscientização, porque esta consiste no desenvolvimento crítico da tomada de consciência" (FREIRE, 1980, p. 25).

Com efeito, o conceito de conscientização teorizado por Paulo Freire, num processo epistemológico longo e dinâmico de construção e reconstrução, toma o papel da educação como sendo estratégico para desencadear aquilo que ele designou como o processo de conscientização. Nesse processo, Paulo Freire considera que o grau de compreensão que os indivíduos possuem da realidade vai evoluindo, segundo estágios individuais e crescentes de consciência, do seguinte modo: a partir do que começa por ser uma consciência ingénua intransitiva, um grau característico da sociedade fechada, passando por uma fase de rutura e reestruturação à qual corresponde uma consciência transitiva, um grau característico das sociedades que estão em trânsito para a modernização, culminando, por fim, na consciência crítica, o grau atribuído às sociedades democráticas. Nesse processo de conscientização, Paulo Freire estabelece uma correspondência entre o tipo manifesto de sociedade existente e o estágio da consciência crítica em que se encontram os seus cidadãos. Não obstante esse entendimento inicial, há, no itinerário do pensamento freiriano, uma clara progressão para o social, que se torna cada vez mais manifesta. De um entendimento do conceito de conscientização, excessivamente consagrado às transformações internas dos seres humanos e da sua consciência individual, o pensamento freiriano passaria a um entendimento mais vocacionado para incorporar os "interesses de classe", na direção 
dos interesses das camadas populares, isto é, interesses ético-emancipatórios, de caráter contra-hegemónico e, portanto, mais relacionado, por um lado, com a temática da consciência de classe e, por outro lado, com a problemática da transformação social, ambas conceptualizadas pela tensão dialética que existe entre permanência e mudança de estruturas nas formações sociais.

\section{Um legado sólido construído com base na autorreflexividade e indagação}

Paulo Freire reconhece, nos seus escritos, que recebeu diversas críticas ao seu trabalho que visavam, precisamente, essa característica do seu pensamento inicial. Não obstante, e revelando, no nosso entender, a coerência de um pensamento aberto e não dogmático, Paulo Freire revê esses aspetos, reformulando alguns pressupostos teóricos, com base em autores inscritos em correntes neomarxistas do pensamento social, apresentando, desde então, uma nova visão que faz uma notável ampliação política e sociológica dos seus temas centrais. Ele próprio afirmaria a esse respeito, num dos seus muitos diálogos publicados, o seguinte: "nos primeiros trabalhos teóricos foram raras as referências ao caráter político da educação e não tomei em conta o problema das classes sociais e a sua luta (...) fi-lo porque estava ideologizado, na verdade, ingénuo como um pequeno-burguês intelectual" (FREIRE, 1990, p. 154).

Esse percurso intelectual, dado a temas centrais da sua filosofia políticopedagógica, permite aos estudiosos do pensamento freiriano identificar diversas fontes teóricas, e escolas de pensamento social nas quais Paulo Freire foi procurar auxílio para compreender e apreender melhor as forças sociais que contribuem para a criação da situação de oprimido, ou seja, aquela em que se encontram os indivíduos e os coletivos excluídos de participarem, imbricando-se e interferindo nas decisões dos centros de poder políticos, económicos e sociais. Assim, segundo Scocuglia (2005), o referencial de influências teóricas de Paulo Freire transita, no que ao conceito de conscientização diz respeito, de uma inspiração hegeliana, centrada na distinção dialética entre "consciência senhorial" e "consciência servil", para uma inspiração luckacsiana, concentrada na diferenciação entre "interesse de classe" e "necessidade de classe" que

Luckács propõe na sua reelaboração do conceito de "consciência de classe" (SCOCUGLIA, 2005, p. 21-35). Nessa reformulação conceptual, resultante dessas 
distintas incorporações teóricas, há diversas categorias que sofrem alteração na forma como são analiticamente tratadas no discurso freiriano. É o caso, por exemplo, da categoria liberdade, que remete mais para a esfera do individual, que vai dando gradualmente lugar à categoria libertação, que sugere mais diretamente uma esfera coletiva, ancorada nos conflitos sociais de classe.

Em termos da matriz de influências teóricas, mais marcantes, ao longo da trajetória do processo de construção dos pressupostos políticos da teoria freiriana, parece-nos plausível falar de três etapas principais. Essas etapas marcam, assim, três tónicas no registo freiriano, que evolui no sentido de superar um certo idealismo inicial transitando para a consolidação de uma abordagem dialética da realidade, sendo que: numa primeira etapa, a sua obra é mais influenciada pelos contributos do personalismo cristão, ou seja, por um pensamento social de raiz católica e um mapa teórico de intersecção entre a fenomenologia e o existencialismo, em que predominam também algumas teses do pensamento utópico (TORRES, 1996, p. 117-149); numa segunda etapa do seu pensamento político, é mais vincada a influência de alguns preceitos marxistas e teses gramscianas, emergindo com muita intensidade, nessa fase, uma análise e desvelamento da realidade da opressão que conjuga as preocupações analíticas de caráter super-estrutural com as aproximações de cariz infraestrutural no tratamento analítico de categorias como, por exemplo, a categoria trabalho (GERHARDT, 1996, p. 159-170); e numa terceira e última etapa do seu itinerário intelectual, sobressai a influência dos debates críticos contemporâneos, tanto do debate oriundo das propostas dos novos movimentos sociais e, em especial, do contributo da abordagem feminista ao pensamento social, como do debate procedente da crise paradigmática, em particular o que contrapõe o paradigma da modernidade ao paradigma da pós-modernidade (SCOCUGLIA, 2005, p. 36-42).

Ora, na realidade essa demarcação em três etapas principais que sugerimos serve-nos, sobretudo, para frisar a forma como o pensamento freiriano se vai matizando e complexificando ao longo do tempo, e por essa via serve-nos para sublinhar que uma tomada parcial de escritos de Paulo Freire, especialmente das suas obras seminais, dificilmente conduzirá a uma compreensão efetiva do seu pensamento, mas apenas a uma fragmentação teórico-conceptual que pode, essa sim, conduzir facilmente a uma apropriação estereotipada da pedagogia da libertação de Paulo Freire, que frequentemente tem produzido, como lamenta Paulo Freire, discursos que constituem 
uma autêntica redução conceptual da sua abordagem político-pedagógica. Como ele próprio refere, esse caminho leva "a todo o tipo de interpretações e práticas reacionárias que levaram [já] a muitas distorções de sentido" (FREIRE, 1990, p. 154).

Esse fenómeno, que de facto se verificaria após a internacionalização da sua obra, teve pelo menos dois momentos de maior expressão, um ocorrido logo no decurso da década de 1970 e outro, a partir da década de 1980, acentuando-se após a sua morte. No primeiro momento, há a assinalar as simplificações que o conceito de conscientização, tornado um dos símbolos da sua teoria, viria a sofrer no discurso de diversos ativismos mecanicistas e acerca do qual o próprio Paulo Freire comentaria: "falava-se ou se escrevia de conscientização como se fosse ela uma pílula mágica a ser aplicada em doses diferentes com vistas à mudança do mundo. Mil pílulas para um patrão reacionário. Dez para um líder sindical autoritário. Cinquenta pílulas para um intelectual cuja prática contradiz o discurso, etc.” (FREIRE; MACEDO, 1994, p. 114). Como consequência, e durante algum tempo, Paulo Freire conta que deixaria, inclusive, de utilizar aquele conceito nos seus escritos e procuraria aclarar, em seminários, por um lado, os pressupostos do processo de conscientização que tinha conceptualizado e, por outro lado, os termos segundo os quais se deve diferenciar o mero ativismo de uma práxis autêntica, essa última implicando sempre uma relação dialética entre teoria e prática, ou seja, entre reflexão e ação.

Quanto ao segundo momento, de forte expressão hodierna, há a assinalar, de igual modo, uma certa inflexão de significado dada ao conceito de conscientização, que da esfera social e política, para a qual progrediu no âmbito do pensamento freiriano, parece ter, paradoxalmente, voltado à esfera do individual e do metodológico, no âmbito dos discursos mecanicistas sobre educação produzidos no contexto do paradigma da aprendizagem ao longo da vida. Paulo Freire foi também sensível a essa segunda dimensão da mistificação do seu conceito de conscientização, acerca da qual comentaria criticamente: "a tentativa de converter a bem conhecida educação para a libertação num problema puramente metodológico (...) pretende eliminar o conteúdo político da educação para que a expressão 'educação para a libertação' já não signifique nada" (FREIRE, 1990, p. 133). Pensamos ser imprescindível não desatender, na análise das atuais práticas educativas, ao facto de que alguns pressupostos freirianos são, hoje, apropriados por visões marcadas por um psicologismo ou um objetivismo mecanicista (BARROS, 2012b) que, de resto, Paulo Freire sempre negou e rejeitou, insistindo 
Barros, R.

sempre na promoção de um pensamento dialético e na defesa de uma ética democrática e radical (BARROS, 2012c; 2013).

De facto, os pressupostos políticos da abordagem político-pedagógica de Paulo Freire, dos quais o conceito de conscientização é a chave mestra, são elaborados no âmbito de um pensamento que tem duas características fundamentais: é um pensamento complexo por excelência, na medida em que conecta no mesmo mapa temático abordagens antropológicas e sociológicas, teológicas e políticas, filosóficas e epistemológicas; e é um pensamento dialético, na medida em que há nele um permanente respeito pela totalidade da realidade que se quer desvelar, ou seja, a sua abordagem assume sempre a unidade dialética contraditória que existe no real (BARROS, 2018). Um real que Paulo Freire sublinha, recorrentemente nos seus textos, que não deve ser abordado dicotomizando as suas contradições, mas apenas os seus antagonismos.

Este é, a nosso ver, um aspeto marcante do seu pensamento crítico, visível nos seus últimos escritos, em que a sua reflexão procura explicitar a união dialética entre entidades contraditórias, como, por exemplo: entre subjetividade e objetividade, ou entre saber e ignorância. Nos anos 1980 e 1990 ganha, de igual modo, proeminência a articulação dialética entre uma "linguagem da crítica", que denuncia, e uma "linguagem da possibilidade", que anuncia, e que estão, desde então, transversalmente presentes no universo temático do pensamento freiriano.

É o eixo de abordagem político-pedagógico que orienta, portanto, em Paulo Freire, toda a reflexão sobre educação, que é elaborada, sublinhamos, em redor de dois grandes temas geradores: a dominação e a libertação; e em torno de um núcleo fundamental de temáticas, às quais Paulo Freire retorna dialeticamente no processo de construção do seu pensamento, entre as quais se podem salientar, por exemplo, a história, a cultura, a democracia, a utopia, o conhecimento ou a ética. Ora, do diálogo que Paulo Freire estabelece com as suas influências teóricas, de que destacámos, sem pretensão de exaustividade, as principais matrizes inspiradoras, resultaria um entendimento original e crítico da educação. Um entendimento pioneiro com um profundo impacto no campo da pedagogia-educação social (BAPTISTA, 2005; CARIDE, 2005; BARROS, FRAGOSO, 2018; 2021) e no campo da educação de adultos (LIMA, 2005; BARROS, 2016; BARROS, LIMA, AZEVEDO, 2020) que, em 
grande medida, encontra-se condensado na relação entre o seu conceito de politicidade da educação e o seu conceito de história como possibilidade.

Trata-se de uma ideia central e estruturante que, para ser compreendida nas implicações que tem na construção de um entendimento sobre a educação como uma forma de intervenção no mundo (seja contribuindo para reproduzir a ordem social, seja contribuindo para a sua transformação), requer que se atenda, antes de mais, à forma como Paulo Freire conceptualiza a noção de história e de consciência histórica que, nos seus termos, assenta num duplo pressuposto: primeiro, que o homem é um ser histórico, incompleto e em projeto, e a sua subjetividade, desde que não domesticada, tem um papel interferente na história. Como Paulo Freire afirmou, ao reconhecer a historicidade dos homens, reconhecem-se os mesmos homens como "seres que estão sendo, como seres inacabados, inconclusos, em e com uma realidade que, sendo histórica, é igualmente inacabada" (FREIRE, 2001a, p. 72). O segundo pressuposto, complementar do primeiro, entende que os seres humanos o são "em situação". Nas palavras de Paulo Freire, os homens "se encontram enraizados em condições tempo-espaciais que os marcam e a que eles igualmente marcam (...) [os homens] serão tanto mais quanto não só pensarem criticamente sobre sua forma de estar, mas criticamente atuem sobre a situação em que estão" (id., ibid., p. 101). É, pois, essencialmente da problematização suscitada pelo binómio consciência de si/consciência do mundo que se desenvolve a ideia da história como possibilidade por meio da qual Paulo Freire recusa o determinismo próprio da matriz marxista clássica e afasta igualmente a compreensão mecânica-positiva-linear da história, própria da matriz neoliberal, ou de um certo pósmodernismo reacionário, como também lhe chama, que concebe a história como um futuro inexorável perante o qual não há outra alternativa senão adaptar-se.

Paulo Freire alerta-nos, no entanto, para a necessidade de dialetizar reflexão e ação no tratamento crítico da história como possibilidade quando afirma que,

\footnotetext{
"esta inteligência da história, que descarta um futuro predeterminado não nega, porém, o papel dos fatores condicionantes a que estamos homens e mulheres submetidos (...) reconhece a importância da decisão como ato que implica rutura, a importância da consciência, da subjetividade e da intervenção crítica dos seres humanos na reconstrução do mundo" (1997a, p. 97).
} 
Como nota Lima, ao criticar o que designou de uma educação indecisa, ou seja, "uma educação a que falta a decisão ou deliberação dos atores educativos (...) uma educação subordinada e frequentemente alienada" (LIMA, 2011, p. 4), a poderosa constatação que faz Paulo Freire de que "como seres humanos somos condicionados, mas não determinados (...) permite problematizar o presente e o futuro, desnaturalizando-os, bem como atribuir protagonismo e responsabilidade à autonomia e à decisão" (id., ibid., p. 11).

História e liberdade surgem, assim, no universo temático nuclear da filosofia político-pedagógica de Paulo Freire como temáticas inter-relacionadas, em que a emersão crítica da realidade situacional em que os oprimidos se encontram imersos lhes permite esperançar e agir para obter a sua libertação. Há, nos escritos de Paulo Freire, como afirma Mayo, toda uma "teoria do sujeito" (MAYO, 1999, p. 90), na qual se defende que, para serem sujeitos da sua libertação, é necessário que os oprimidos saibam reconhecer o sentido da história, para nela se inserirem criticamente como sujeitos que fazem e refazem o mundo, como o próprio Paulo Freire afirma:

\footnotetext{
Da imersão em que se achavam, emergem, capacitando-se para se inserirem na realidade que se vai desvelando. Desta maneira, a inserção é um estado maior que a emersão e resulta da conscientização da situação. É a própria consciência histórica. Daí que seja a conscientização o aprofundamento da tomada de consciência, característica, por sua vez, de toda emersão (2001a, p. 102).
}

Ora, essas assunções em torno da ideia da história como possibilidade têm consequências substantivas em nível social e político, pois abrem espaço para a práxis transformadora, que, uma vez iniciada por parte dos oprimidos, poderá levar à superação da situação de opressão, num processo de engajamento orientado para a dissolução das estruturas sociais que antes impediam o processo de emancipação, ou seja, de pronúncia ativa do mundo.

Em termos de teoria política, há nesses pressupostos freirianos importantes implicações filosófico-conceptuais, já que, mediante esse tipo de processo de conscientização social e político emergem com maior clareza as contradições sociais, os termos e os modos da opressão dos sectores populares pelas estruturas e elites sociais. Uma elite dominadora que, recorrendo a mecanismos diversos de controlo e de 
ocultação das possibilidades que a história em si contém enquanto devir, ou seja, enquanto acontecimento humano, representa, na verdade, uma minoria muito bemsucedida a impedir a efetiva participação política e social da maioria. Ao se assumir, ao longo da sua obra, como adepto de uma conceção de democracia radical, construída com base na ideia de participação como forma de ingerência nos processos de decisão, Paulo Freire critica e recusa as teorias elitistas de democracia e, de acordo com Lima, "não poupou as lideranças de tipo dirigista e vanguardista, bem como todas as formas de 'domesticação' (a conquista, o slogan, a propaganda...) e todo o tipo de organizações burocráticas e oligárquicas" (LIMA, 2011, p. 4).

Paulo Freire, ao problematizar o real e teorizar acerca de uma pedagogia que é a do oprimido, vai contribuir de uma forma pioneira, no âmbito do corpus teórico da pedagogia-educação social e da educação de adultos, para desocultar esses mecanismos que relacionam pedagogia e poder, inclusive criando todo um novo vocabulário filosófico-conceptual que permite ao mundo dos oprimidos adquirir visibilidade. Nesse contexto, Paulo Freire denuncia que

\footnotetext{
O que interessa ao poder opressor é enfraquecer os oprimidos mais do que já estão, ilhando-os, criando e aprofundando cisões entre eles, através de uma gama variada de métodos e processos. Desde os métodos repressivos da burocratização estatal, à sua disposição, até as formas de ação cultural por meio das quais manejam as massas populares, dando-lhes a impressão de que as ajudam (2001a, p. 138-139).
}

Ora, é precisamente nesse âmbito que Paulo Freire pode ser considerado um dos mais significativos filósofos da libertação, engajado na construção de uma nova teoria da ação cultural que sirva aos interesses dos oprimidos, ou seja, da maioria dos desapossados e esfarrapados desse mundo, homens e mulheres impedidos de adquirirem uma consciência histórica que lhes permita realizarem a vocação ontológica da espécie humana, que consiste na sua humanização, como por diversas vezes Paulo Freire colocaria essa questão nos seus vários escritos, num dos quais pode ler-se, por exemplo: “esta vocação para o ser mais que não se realiza na inexistência de ter, na indigência, demanda liberdade, possibilidade de decisão, de escolha, de autonomia" (FREIRE, 1997b, p. 10).

A inclusão de alguns aspetos de influência marxista e neomarxista na análise freiriana da realidade manifesta-se também com um certo matizado gramsciano, em 
Barros, R.

particular nessa linha da sua argumentação, em que Paulo Freire reelabora as suas ideias vincando o processo político de conscientização, e, ao fazê-lo, considera dialeticamente o contexto teórico e o contexto social concreto em que tal processo se desenrola, ou seja, procura compreender a dialeticidade que existe entre infra e supraestrutura, explicitando as classes sociais como a área na qual a opressão dos homens é levada a cabo, o que lhe permite identificar, em termos conceptuais, consciência histórica com consciência política e esta, por sua vez, com consciência de classe e com consciência revolucionária (FREIRE, 1990). O seu compromisso, no entanto, não é com a construção de uma sociedade sem classes, mas, sim, com a construção de uma sociedade radicalmente democrática.

\section{Educar para a justiça social e a cidadania global}

Numa democracia radical, há justiça social e há sujeitos em interação, pelo que a finalidade de uma "verdadeira revolução", que Paulo Freire atribui a "homens radicais", implica precisamente transformar a realidade opressora possibilitando a passagem dos seres humanos da condição de objetos ao estatuto de sujeitos. Trata-se de uma transformação que ocorre primeiro ao nível da consciência e que implica o movimento da classe em si para uma classe para si, em que os oprimidos desenvolvem gradualmente, quer um sentido de identidade coletiva e um reconhecimento da sua opressão, quer uma ideologia contra-hegemónica que lhes permite refletir criticamente para desmistificar as ideias criadas pelas classes dominadoras e organizarem a ação, de uma forma muito específica: para consumar o processo da libertação coletiva, tanto dos oprimidos como dos opressores, "gerando de seu ser menos a busca do ser mais de todos" (FREIRE, 2001a, p. 34). Nesse particular, Paulo Freire desenvolve a ideia gramsciana de intelectual orgânico, reconhecendo um papel para "a liderança verdadeiramente revolucionária", mas concebendo os oprimidos como os protagonistas da sua própria conscientização e libertação.

Há nesses pressupostos políticos da abordagem freiriana uma rejeição de todo um vanguardismo de matriz leninista, que tende, ao invés, a privilegiar a intelligentsia como a única fonte viável da ideologia e da ação contra-hegemónica. No universo temático do pensamento de Paulo Freire encontramos, por isso, em diversos momentos, na teorização acerca da ação libertadora, uma conceção da relação entre intelectuais e 
classes populares, em que o compromisso e o engajamento dos primeiros com a causa da libertação implicam o seu total encontro solidário com os homens impedidos de ser mais. Paulo Freire entende que a verdadeira revolução, que pretende transformar a realidade desumanizante dos homens "nem pode ser feita para o povo pela liderança, nem por ele, para ela, mas por ambos, numa solidariedade que não pode ser quebrada" (FREIRE, 2001a, p. 126) e vinca, ainda a esse respeito, que "o compromisso, próprio da existência humana, só existe no engajamento com a realidade, de cujas 'águas' os homens verdadeiramente comprometidos ficam 'molhados', ensopados. Somente assim o compromisso é verdadeiro" (FREIRE: 1999a, p. 19).

\section{Considerações finais}

O vocabulário político das ideias freirianas, que caracterizam o processo de conscientização que a sua filosofia propõe, deixa clara a sua opção política a favor dos oprimidos. O tipo de engajamento que nela defende nega o imobilismo e exige radicalidade de todos os intervenientes, na medida em que "ser um revolucionário significa opormo-nos à opressão e à exploração e ser a favor da libertação das classes oprimidas, em termos concretos e não em termos idealistas" (FREIRE, 2001a, p. 54).

Trata-se de promover, por todos os meios, dos quais a educação ocupa um lugar estratégico, a convivência democrática, mas confiando na capacidade do homem conscientizado para empreender uma mudança radical nas suas condições de vida, tomando a leitura crítica da história como uma forma de reivindicar identidade e poder (FREIRE e MACEDO, 1994). No método de alfabetização proposto por Paulo Freire, portanto, gera-se conscientização política, no nosso entender, por intermédio da forma como é colocada no centro do trabalho educativo a relação dialética entre subjetividade e objetividade, que, alicerçada no respeito pelos valores e comportamentos históricos e culturais das populações, desperta nelas a necessidade de um quefazer, que, nos termos freirianos, é um fazer com reflexão direcionado para um processo de emancipação e viabilizado por uma tomada de consciência que é pedagógica, ética e política, e por isso está imbricada e implicada numa prática educativa propiciadora de uma práxis em que possamos aprender a ler certo o mundo.

Por fim, resta sublinhar, nessa celebração do centenário do nascimento de Paulo Freire, que da sua obra (da qual selecionamos, para a análise, nesta reflexão, apenas o 
Barros, R.

conceito de conscientização e o inerente conceito de politicidade da educação) resulta um testemunho e um legado em prol de um humanismo radical que nos inspira, no século XXI, enquanto cidadãos(ãs) em busca de valores cívicos e democráticos, ao mesmo tempo em que nos lembra, enquanto educadores(as) e investigadores(as), que a educação deve ser entendida na sua plenitude como projeto que contribui para a libertação e como ato de (re)conhecimento (BARROS, 2020). Nessa senda, parece-nos imprescindível, no atual contexto multi-crises globais, desconstruir as visões despolitizadas da educação que circulam atualmente, de forma hegemónica, o abrigo do paradigma da aprendizagem ao longo da vida e que insulariza os indivíduos, aprisionando-os numa competitividade desenfreada que impede colaborações coletivas e solidárias que visem a ultrapassar as crises para deixar como legado às gerações vindouras um mundo melhor.

\section{Agradecimento}

Este artigo é financiado por Fundos Nacionais através da Fundação para a Ciência e a Tecnologia (FCT ) no âmbito do Projeto UIDB/05739/2020.

\section{Referências}

BAPTISTA, I. Dar Rosto ao Futuro, A Educação Social como Compromisso Ético. Porto: Profedições, 2005.

BARROS, R. Genealogia dos Conceitos em Educação de Adultos: Da Educação Permanente à Aprendizagem ao Longo da Vida - Um estudo sobre os fundamentos político-pedagógicos da prática educacional. Lisboa: Chiado Editora, 2011. Disponível em: http://hdl.handle.net/10400.1/14097. Acesso em: 15-06-2021.

BARROS, R. From Lifelong Education to Lifelong Learning: Discussion of some effects of today's neoliberal policies. RELA - European Journal for Research on the Education and Learning of Adults, v. 3, n. 2, p. 119-134, 2012a. Disponível em: http://www.rela.ep.liu.se/article.asp?DOI=10.3384/rela.2000-7426.rela0071. Acesso em: 16-06-2021.

BARROS, R. Subsídios Breves para o Debate de Princípios e Valores na Formação Política do(a) Educador(a) Social. Lisboa: Chiado Editora, 2012b. Disponível em: http://hdl.handle.net/10400.1/14098. Acesso em: 28-06-2021.

BARROS, R. (2012c). A Educação Social e Permanente de Adultos (ESPA) como um Quefazer Filosófico Transformador de Situações-limite. Revista HASER, Revista Internacional de Filosofia Aplicada, n. 3, p. 77-108, $2012 \mathrm{c}$. 
BARROS, R. Contribuciones actuales del pensamiento freiriano en la educación de filosofía con niños - para una democratización de la democracia en tiempos de crisis. In: RASTROJO BARRIENTOS, J. (Ed.). Filosofía para Niños y Capacitación Democrática Freiriana. Madrid: Liber Factory, 2013. p. 23-60.

BARROS, R. Refletir com (im)pertinência intervir com ousadia: por uma educação transformadora. In: GARRIDO, N. C.; SILVA, O. M.; LIMA, P. G.; EVANGELISTA, F. (Eds.). A Educação de Jovens e Adultos para além dos Muros da Escola: perspetiva da Educação Social. Brasil: Editora Expressão \& Arte, 2016. p. 253-276.

BARROS, R. Revisitando Knowles e Freire: Andragogia versus pedagogia, - ou o dialógico como essência da mediação sociopedagógica. Educação e Pesquisa, v.44 (e173244), p. 1-19, 2018. Disponível em: http://dx.doi.org/10.1590/S16784634201844173244 Acesso em: 28-06-2021.

BARROS, R. Resgatar a Meta-Reflexão Freiriana em Cinco Atos - Um marco perene para pensar dilemas do educador-investigador hodierno. Educação, Sociedade \& Culturas, Número Especial Celebrando Paulo Freire: Novos e velhos desafios na educação - Volume II: Paulo Freire: Da filosofia política à recontextualização no tempo atual, 56, p. 83-100, 2020. Disponível em:

https://www.fpce.up.pt/ciie/sites/default/files/Rosanna\%20Barros.pdf Acesso em: 2906-2021.

BARROS, R.; FRAGOSO, A. (Eds.). Investigação em Educação Social - prática e reflexão. Faro: Universidade do Algarve, 2018. Disponível em:

http://hdl.handle.net/10400.1/11020 Acesso em: 29-06-2021.

BARROS, R.; FRAGOSO, A. (Eds.). Investigação em Educação Social - prática e reflexão. Volume II. Faro: Universidade do Algarve, 2021. Disponível em:

http://hdl.handle.net/10400.1/14974 Acesso em: 30-06-2021.

BARROS, R.; LIMA, P. G.; AZEVEDO, M. (Org.). Rumos da Educação e Formação de Jovens e Adultos em Portugal e no Brasil - um balanço comparado de políticas e práticas. Natal: Editoria IFRN-Brasil, 2020. Disponível em: https://memoria.ifrn.edu.br/handle/1044/1835 Acesso em: 30-06-2021.

BOFF, L. Igreja: carisma e poder. Ensaios de Eclesiologia Militante. Petrópolis: Editora Vozes, 1982.

CARIDE, J. A. Las Fronteras de la Pedagogía Social. Barcelona: Gedisa, 2005.

FREIRE, P. Educação como Prática da Liberdade. Rio de Janeiro: Paz e Terra, 1968.

FREIRE, P. Educação Política e Conscientização. Lisboa: Sá da Costa, Cadernos Livres (6), 1975.

FREIRE, P. Ação Cultural para a Libertação. Lisboa: Moraes Editores, 1976. 
Barros, R.

FREIRE, P. Cartas à Guiné-Bissau. Registos de uma Experiência em Processo. Rio de Janeiro: Paz e Terra, 1978.

FREIRE, P. (1980). Conscientização. São Paulo: Moraes, 1980.

FREIRE, P. La Naturaleza Política de la Educación - Cultura, Poder y Liberación. Barcelona: Ediciones Paidós, 1990.

FREIRE, P. Extensão ou Comunicação? Rio de Janeiro: Paz e Terra, 1992.

FREIRE, P. Professora Sim, Tia Não: Cartas a quem ousa ensinar. São Paulo: Olho d'Água, 1993.

FREIRE, P. Cartas a Cristina. Rio de Janeiro: Paz e Terra, 1994.

FREIRE, P. Á Sombra desta Mangueira. São Paulo: Olho d'Água, 1995.

FREIRE, P. Política e Educação. São Paulo: Cortez Editora, 1997.

FREIRE, P. Pedagogia da Autonomia - Saberes necessários à prática educativa. Rio de Janeiro: Paz e Terra, 1997b.

FREIRE, P. Educação e Mudança. Rio de Janeiro: Paz e Terra, 1999a.

FREIRE, P. A Educação na Cidade. São Paulo: Cortez Editora, 1999b.

FREIRE, P. A Importância do Ato de Ler - em três artigos que se completam. São Paulo: Cortez Editora, 2000.

FREIRE, P. Pedagogia do Oprimido. Rio de Janeiro: Paz e Terra, 2001a.

FREIRE, P. Pedagogia da Esperança - Um Reencontro com a Pedagogia do Oprimido. Rio de Janeiro: Paz e Terra, 2001b.

FREIRE, P.; MACEDO, D. Alfabetização - Leitura do Mundo, Leitura da Palavra. Rio de Janeiro: Paz e Terra, 1994.

GERHARDT, H-P. Uma voz Europeia: Arqueologia de um Pensamento. In: Moacir Gadotti et al. (org.). Paulo Freire - Uma Biobibliografia. São Paulo: Cortez Editora, 1996. p. $149-170$

LIMA, L. C. A Educação de Adultos em Portugal (1974-2004): entre as lógicas da educação popular e da gestão de recursos humanos. In Educação e Formação de Adultos. Mutações e Convergências (31-60). Lisboa: Educa, 2005.

LIMA, L. C. Crítica da Educação Indecisa: a propósito da Pedagogia da Autonomia de Paulo Freire, Revista e-curriculum, 2011, p. 1-12.

MAYO, P. Gramsci, Freire \& Adult Education - Possibilities for Transformative Action. London: Zed Books, 1999. 
SCOCUGLIA, A. C. A Construção da História das Ideias de Paulo Freire. In: Streck, D. (org.). Paulo Freire - Ética, Utopia e Educação. Petrópolis: Editora Vozes, 2000, p. 2952.

SCOCUGLIA, A. C. Paulo Freire e a "Conscientização" na Transição Pós-moderna. Educação, Sociedade e Culturas, v. 23, p. 21-42, 2005.

TORRES, C. A. A Voz do Biógrafo Latino-americano: Uma Biografia Intelectual. In: Moacir Gadotti et al. (org.). Paulo Freire - Uma Biobibliografia. São Paulo: Cortez Editora, 1996, p. 117-148.

Recebido em 30/08/2021

Aprovado em 15/09/2021

Publicado em 29/10/2021 